\title{
A HUMANIDADE NA ANIMALIDADE KANT E A ANTROPOLOGIA DO BEM E DO MAL
}

\author{
Diogo Sardinha \\ Freie Universität Berlin (pós-doutorando)
}

\begin{abstract}
A Antropologia de Kant oferece-nos uma entrada sedutora para abordar o papel da ciência e da filosofia no jogo da guerra e da paz ${ }^{1}$. Ela diz respeito ao que poderia chamar-se de modo geral uma tendência do homem para a violência ou, se quisermos ser mais precisos, uma inclinação do homem pelo mal. Nos limites de uma simples introdução ao tema é impossível retomar em pormenor todo o desenvolvimento destes conceitos, motivo pelo qual me limitarei a apresentar algumas reflexões sobre o uso que deles faz Kant na última secção do seu livro, intitulada «O carácter do género». É daí que extraio as seguintes linhas:
\end{abstract}

Mesmo numa constituição civil-burguesa, grau mais elevado do desenvolvimento artificial das boas disposições no género humano para o fim último do seu destino, a animalidade é, nas suas expressões, anterior e no fundo mais potente do que a pura humanidade; e apenas por enfraquecimento o gado amansado é mais útil ao homem do que o selvagem. A vontade própria está sempre prestes a voltar-se contra o seu próximo, e a todo o momento se esforça, na sua pretensão a uma liberdade incondicionada, por ser não apenas independente, mas ainda senhora de outros seres que por natureza the são iguais [...] (Kant, Anth., p. 327)2.

\footnotetext{
${ }^{1}$ Uma versão preliminar deste texto foi apresentada no colóquio «Guerra e Paz: o papel da ciência e da arte» realizado pela Fundação Alexander von Humboldt no Instituto Goethe de Paris em Novembro de 2007, sob a direcção de Olivier Remaud e Soraya Nour.

${ }^{2}$ A edição utilizada da Anthropologie in pragmatischer Hinsicht é a da Akademie Textausgabe, vol. VII. As traduções são nossas, cotejadas com a tradução francesa de Michel Foucault.
}

Philosophica, 31, Lisboa, 2008, pp. 51-64 
In einer bürgerlichen Verfassung, welche der höchste Grad der künstlichen Steigerung der guten Anlagen in der Menschengattung zum Endzweck ihrer Bestimmung ist, ist doch die Thierheit früher und im Grunde mächtiger als die reine Menschheit in ihren Äußerungen, und das zahme Vieh ist nur durch Schwächung dem Menschen nützlicher, als das wilde. Der eigene Wille ist immer in Bereitschaft, in Widerwillen gegen seinen Nebenmenschen auszubrechen, und strebt jederzeit, seinen Anspruch auf unbedingte Freiheit, nicht blos unabhängig, sondern selbst über andere ihm von Natur gleiche Wesen Gebieter zu sein [...].

Lembremos, antes de comentar estas linhas, que a ciência antropológica à qual se presta atenção aqui adquire para Kant um alcance incontestavelmente especulativo, no horizonte do qual devemos sempre pressentir a sua pergunta «o que é o homem?». Tratando agora da citação, notemos o quanto ela revela o interesse de Kant pelo que parece ser uma antropologia da violência. Por estas palavras devemos entender uma pesquisa sobre o que o homem é enquanto ser no qual o abuso de poder é não só uma capacidade inscrita na sua estrutura primeiramente e fundamentalmente animal, mas também uma tentação constante que o impele a infringir os limites da sua liberdade como a dos seus iguais. Kant não poderia ser mais explícito quando afirma que «mesmo numa constituição civil-burguesa», isto é, num regime constituído por cidadãos e que simultaneamente permite a estes últimos, compreendidos de forma universal como género humano, de desenvolver as suas disposições para o bem, «a animalidade é, nas suas expressões, anterior e no fundo mais potente do que a pura humanidade». Por outras palavras, mesmo quando as condições políticas e civis estão reunidas para que as boas disposições do homem se desenvolvam, uma tensão prodigiosa permanece sempre, no interior deste último, entre a humanidade e a animalidade, tensão que parece resolver-se aqui de maneira imediata em benefício desta que, nas suas manifestações, é a um tempo primeira e mais forte. Pode assim dizer-se que Kant nos propõe, neste texto, uma antropologia da violência, ou ainda uma antropologia do abuso da força, na medida em que inscreve a condição de possibilidade deste abuso no carácter primeiro e fundamental do género humano.

É por conseguinte natural que a Antropologia de um ponto de vista pragmático ponha em relevo a violência própria do homem, no que poderíamos chamar, invertendo a expressão precedente, uma violência da antropologia. Esta expressão encerrará então uma duplo sentido: em primeiro lugar trata-se de uma violência cometida por um homem contra o seu vizinho, ou de uma violência entre homens. A imagem dada por Kant não está aqui talvez muito longe, sob certos aspectos, do estado de natu- 
reza, na medida em que nos dois casos sobrevém a todo o instante um choque entre as pretensões de diferentes indivíduos a uma liberdade sem limites, com as tentativas que as acompanham de exercer sobre os outros um poder dominante. Tudo acontece como se, mesmo na forma constitucional mais conseguida (porquanto ela é a mais humana no sentido em que convém mais perfeitamente à realização da «pura humanidade» do homem), o carácter animal ou ainda selvagem do ser humano acarretasse continuamente consigo um resíduo de natureza, e até como se a animalidade primeira e mais potente transportasse sempre um excesso de natureza para o âmago da sociedade civil ${ }^{3}$.

Há porém um segundo sentido da noção de violência da antropologia: para impedir a dupla sobreposição da animalidade à humanidade e da liberdade de uns à liberdade de outros, torna-se necessário fazer intervir uma terceira força, um outro poder, de novo exercido pelo homem sobre o homem, nada menos do que a força de domesticação. «Apenas por enfraquecimento, sublinha Kant, o gado amansado é mais útil ao homem do que o selvagem.» Por isso será necessário amansar o ser humano, torná-lo menos feroz, mais familiar em sentido estrito - apto à vida em família e, para lá da família, mais sociável - capaz de viver pacificamente em sociedade - para fazer dele precisamente o que ele é, um homem. Dito de outro modo, a fim de dilatar no homem o espaço da sua própria humanidade, é preciso enfraquecer nele a animalidade, domesticá-lo e cultivá-lo. A cultura começa pela domesticação, ambas representam um enfraquecimento do carácter selvagem do humano. Não temos pois de espantar-nos se o trabalho de Kant sobre o carácter da espécie desemboca num pensamento da educação, sobretudo dos laços estreitos que ela desenvolve com a disciplina (a Zucht, a Disciplin) (Kant, Anth., p. 323), educação acerca da qual ele acrescenta um pouco mais longe que ela «é salutar, mas rigorosa e severa» (heilsam, aber rauh und strenge) (Kant, Anth., p. 328). Ora, como não reparar na nova violência que acompanha este procedimento? Na sua tradução, Foucault foi sensível a este ponto, demasiado sensível talvez, por exemplo ao interpretar Zucht não como disciplina, mas imediatamente como repressão ${ }^{4}$ Não teria sido porém necessário levar a tal extremo o texto de Kant para fazê-lo confessar o que é eviden-

${ }^{3}$ Tal ideia convida a uma confrontação com Rousseau por um lado, e por outro lado com Hobbes, que nos oferecem duas perspectivas divergentes tanto do estado de natureza quanto da bondade ou da maldade originárias do homem. De facto não é por acaso que Kant escreve sobre Rousseau e a figura do bom selvagem em páginas da Antropologia contíguas às que nos servem de inspiração. Outra obra de Kant igualmente crucial para tratar o tema presente é A Religião nos limites da simples razão.

${ }^{4}$ Trad. de M. Foucault, Anthropologie du point de vue pragmatique, Paris, Vrin, 1991 (6 $6^{\mathrm{a}}$ tiragem), p. 163. 
te, que a antropologia estabelece uma relação inegável com a violência, por três vias ao menos. Primeiro, porque a violência jaz no coração do seu objecto (no coração do homem) sob a forma da animalidade primeira e mais potente nas suas expressões, característica do género. Segundo, porque a violência da animalidade é nomeadamente a susceptível de ser exercida por cada um de nós sobre qualquer outro, e isto mesmo na sociedade que em simultâneo representa e promove o desenvolvimento mais elevado das boas disposições humanas. Terceiro e por último, porque a maneira de contrariar esta propensão para o extravasamento põe ela própria em movimento uma outra força - a educação associada ao rigor e à severidade da disciplina - ainda sobejamente próxima de um enfraquecimento por domesticação. Para favorecer a cultura e a civilização é assim necessário ao homem empregar uma força sobre os outros homens, como faz o educador, numa sorte de paradoxo que Kant exprime ao explicar que o educador «deve produzir no outro aquilo de que ele próprio necessita» (Kant, Anth., p. 325). Para mais, o homem feito pode unicamente existir como resultado deste uso da força, desta domesticação e desta disciplina. A antropologia torna assim visível uma tripla violência: a da animalidade no homem (violência primeira), a do extravasamento de cada um sobre os seus próximos (violência sempre possível), enfim a da educação pela disciplina (violência necessária). Somente neste ponto de intersecção nasce o homem. Kant teria tido a virtude de no-lo mostrar, ao conduzir-nos ao centro da violência antropológica entendida como espaço de encontro de uma antropologia da violência com a violência do anthropos.

Até aqui, a nossa leitura pode parecer coerente. Ela não é contudo isenta de problemas, pois não encontraremos, nestas páginas do livro de Kant, uma palavra que reúna os diferentes aspectos que condensámos sob o nome de violência $\mathrm{O}$ que faz a secção final da Antropologia de um ponto de vista pragmático é outra coisa: ela distingue uma «disposição inata» (angeborne Anlage) para o bem e uma «inclinação no homem a cometer o que não é permitido, ainda que ele saiba que não é permitido, isto é uma inclinação pelo mal» - "in ihm ein Hang zur thätigen Begehrung des Unerlaubten, ob er gleich weiß, daß es unerlaubt sei, d. i. zum Bösen, sei" (Kant, Anth., p. 324). Estes dois traços são igualmente naturais no homem. Todavia, o primeiro pertence ao seu carácter inteligivel; e o segundo, ao seu carácter sensivel. Esta partição é, como sabemos, constante, e conduz a uma certa ideia da educação: «o homem, resume Kant, deve portanto ser educado para o bem» - "Der Mensch muß also zum Guten erzogen werden" (Kant, Anth., p. 325.) Neste processo, continua, «trata-se de produzir o bem que o homem não se propôs, mas que, uma vez realizado, se mantém, a partir do mal sempre dividido interiormente contra si mesmo.» - "der Hervorbringung des vom Menschen nicht beab- 
sichtigen, aber, wenn es einmal da ist, sich ferner erhaltenden Guten aus dem innerlich mit sich selbst immer sich veruneinigenden Bösen." (Kant, Anth., p. 328.) Assim compreendida, a educação acompanha e favorece a tendência do género humano para um «desenvolvimento do bem a partir do mal» - "die Entwicklung des Guten aus dem Bösen" (Kant, Anth., p. 329). Na sua constância, esta partição entre bem e mal dissipa antecipadamente qualquer equívoco entre modos diferentes de usar a força. Ainda poderia sustentar-se que a palavra alemã Gewalt se prestaria comodamente a este jogo de correspondências, visto combinar os sentidos múltiplos de força, poder, autoridade e, claro está, violência, sem nunca reduzi-los nem uns aos outros nem a um só. No entanto o termo Gewalt não é utilizado por Kant com esta finalidade, e ficamos desarmados quando desejamos pensar o facto simples do uso da força.

Kant não teria visto o que a sua investigação tornava manifesto? Não teria notado a omnipresença do constrangimento pela força ou a intimidação, chame-se esta animalidade, aversão contra o seu próximo, enfraquecimento por domesticação ou ainda educação por uma disciplina rigorosa e severa? Eis o que seria uma censura precipitada, e no fim de contas injusta, dirigida contra a filosofia crítica. É incontestável que Kant percebeu distintamente esta omnipresença e que optou de modo reflectido por omiti-la em proveito de uma outra configuração antropológica. Talvez o papel da violência enquanto força produtora se tenha tornado para nós tão límpido, que não podemos mais mantê-la no elemento da disjunção, como Kant preferiu ao opor o bem e o mal e ao fazê-los acompanhar cada um pelas forças correspondentes que não teriam entre elas qualquer traço comum significativo. É provável que a nossa leitura não consiga mais desembaraçar-se da ideia nietzscheana do homem como animal domesticado, nem do estudo foucaultiano do homem como produto das disciplinas, nem do paradoxo pelo menos bourdieusiano de uma violência doce pela qual a sociedade nos constitui. Deste ponto de vista, se foi preciso matar o homem, foi porque não se podia mais compreendê-lo a partir da divisão entre o bem e o mal e que se impunha pensar para lá desta fronteira. É com certeza o que explica também a última frase de Foucault no seu comentário à Antropologia, redigido na mesma época em que traduziu o livro de Kant e que, não obstante, permaneceu inédito durante tanto tempo: «A trajectória da pergunta: Was ist der Mensch? no campo da filosofia completa-se na resposta que a recusa e a desarma: der Übermensch.» ${ }^{5}$ Em suma, se Kant decidiu conservar na diferença as forças que educam

${ }^{5}$ «La trajectoire de la question: Was ist der Mensch? dans le champ de la philosophie s'achève dans la réponse qui la récuse et la désarme: der Übermensch.» Foucault, «Introduction à l'Anthropologie de Kant» (1960), in Kant, Anthropologie d'un point de vue pragmatique, Paris, Vrin, 2008, p. 79. 
para o bem e as potências que inclinam para o mal, não há motivo para pensarmos que isso não seria senão uma escolha, correlativa do seu modo de formular a pergunta «o que é o homem?» e de responder-lhe. Temos por conseguinte de concentrar-nos sobre esta interrogação, que como assinalámos desde o início permanece no horizonte da Antropologia.

\section{O homem é o nome de um espaço: nominalismo antropológico}

Com este fim gostaríamos de fazer entrar em curto-circuito a primeira citação, extraída da última seç̧ão da obra, com algumas linhas desta feita retiradas do prefácio. Fazer entrar em curto-circuito significa aproximar imediatamente, por conseguinte de forma brutal, frases distantes umas das outras para fazer com que ressoem em conjunto. Escusado dizer que este método deixa de lado as explanações que constituem a maior parte do livro. Ele é por essa razão arriscado pois, como num curto-circuito em sentido estrito, deixará na penumbra um complexo de ideias importantes. Mas tal exercício fará cintilar o clarão que, por um instante, iluminará o espaço de um problema. Este problema é precisamente o do homem. Eis então a frase em que Kant distingue a fisiologia da pragmática, com vista a definir o quadro no interior do qual se desdobrará a Antropologia:

O conhecimento fisiológico do homem tende à exploração do que a natureza faz do homem; o conhecimento pragmático, à exploração do que ele, enquanto ser de livre actividade, faz de si mesmo, ou do que pode e deve fazer de si mesmo.» (Kant, Anth., p. 119).

Die physiologische Menschenkenntniß geht auf die Erforschung dessen, was die Natur aus dem Menschen macht, die pragmatische auf das, was er als freihandelndes Wesen aus sich selber macht, oder machen kann und soll.

Deslumbrantes nesta passagem são a clareza e a prontidão com as quais nela se indicam os três planos sobre os quais se desenvolverá uma antropologia de um ponto de vista pragmático: há antes de mais o plano dos factos, na medida em que esta forma de reflexão se interessa pelo que o homem $f a z$ de si mesmo; há em seguida o plano da possibilidade, porquanto ela respeita ao que o homem pode fazer de si mesmo; surge por fim o plano do dever, atinente ao que o homem deve fazer de si mesmo. No seu livro, Kant propõe-se conduzir a sua empresa a estes três níveis que, desde logo, nos aparecem como intimamente associados. Ao mesmo tempo, a elaboração crítica pela qual ele distingue os três níveis revela que não existe apenas um campo de resposta à interrogação «que é o homem?», mas que esta, sem nunca abandonar o terreno antropológico assim delimitado, conjuga tanto o empírico com o inteligível como os pla- 
nos do ser, do poder-ser e do dever-ser. Que é o homem? Ele é em simultâneo aquilo que faz, aquilo que pode fazer e aquilo que deve fazer de si próprio, e isto tão-só de um ponto de vista pragmático, pois a mesma pergunta pode ser também considerada de um ponto de vista fisiológico. De tal modo que as respostas variam consoante o ponto de vista a partir do qual a pergunta é formulada 6 .

Esta consideração conduz-nos ao ponto mais importante que temos aqui de abordar. Pois que significa exactamente o ponto de vista, a Hinsicht que determina, no título da obra, uma reflexão que de outra forma permaneceria no plano da generalidade? O ponto de vista é o meio pelo qual um terreno ou um quadro problemático é determinado, quadro no interior do qual cada problema adquire contornos específicos. Se assim é, então menos do que um ser que tenhamos de conhecer por conceitos, o homem é o nome de um problema. Compreendido desta forma, o homem torna-se, para retomar a fórmula do antropo-geógrafo Friedrich Ratzel, um espaço no qual podemos ler o tempo ${ }^{7}$. A Antropologia de Kant, com os seus três planos, a sua humanidade inteligível e sensível, e sobretudo com a sua partilha entre as boas disposições e a inclinação pelo mal, partilha à qual falta uma noção unificadora da violência nela implicada, é uma das configurações históricas do problema «homem» ou uma das formas de pensar o homem. Ora esta configuração muda: o que pertence ao homem como essência ou como acidente, quer o consideremos individualmente, como espécie ou ainda como género; as entidades abarcadas pelo conjunto a que chamamos humanidade, aquelas que aí não cabem e ainda as que, embora a ele pertençam, dela se encontram excluídas pela violência, tudo isto varia segundo a época e o lugar. O espaço do homem transforma-se de acordo com os limites que o instauram, tanto quanto com o seu arranjo interior. Daí os debates ao longo da história sobre a humanidade dos escravos, dos negros, das mulheres ou dos judeus. $\mathrm{Na}$ verdade, nem precisamos de reler a história para nos convencermos disto, porque o mesmo fenómeno pode ser também detectado em menor escala no pensamento de um só autor. Por exemplo, Aristóteles estabelece o problema do homem de duas maneiras diferentes quando define este último como único animal que utiliza a linguagem (Aristóteles, Geração

\footnotetext{
${ }^{6}$ Esta maneira de distinguir os conhecimentos fisiológicos dos pragmáticos parece conferir à Antropologia um lugar excepcional na obra kantiana, pois ela situa sem reserva os estudos práticos ou morais (respeitantes ao poder-ser e ao dever-ser) no interior do campo mais lato da investigação sobre o homem, indo assim explicitamente de encontro por exemplo à introdução da Metafísica dos costumes, para envolver esta metafísica na antropologia.

${ }^{7}$ É a expressão que dá o título ao livro importante de Karl Schlögel, Im Raume lesen wir die Zeit (Munich, Carl Hanser Verlag, 2003), consagrado à Zivilisationsgeschichte e à geopolítica.
} 
dos animais, V, 7, 786 b 20) ou como animal político (Aristóteles, Políti$c a, \mathrm{I}, 2,1253$ a 28). Cada uma destas definições fixa à sua maneira os dados do problema. Quando, nas Palavras e as coisas, Foucault declara que a Idade Clássica não podia pensar o homem, isto não significa que não existisse então nenhum problema do homem, mas tão-somente que aquilo a que, precisamente depois de Kant, se chamou «o homem»- este ente que se compreende a um tempo como objecto do saber e sujeito que dá a todo o saber as suas condições de possibilidade, numa palavra como par empírico-transcendental - designa uma configuração distinta daquela a que a época precedente se referia ao servir-se do mesmo nome ${ }^{8}$. Uma das virtudes maiores dos teóricos da morte do homem foi, exactamente porque precisavam mostrar o carácter limitado da configuração antropológica moderna, a de terem trazido à luz formas diferentes segundo as quais o humano foi e continua a ser captado pelo pensamento em cada idade. Pôde assim constituir-se, no seio da própria modernidade, uma filosofia que renunciou ao programa de saber o que é o homem para consagrar-se ao estudo de uma diferença específica, a qual, em vez de separar o homem do animal ou de Deus, distingue umas das outras as configurações temporais do problema «homem», escrevendo a história a partir de uma dramatização das oposições entre épocas e quadros temporais diversos. É o que faz Heidegger que, em «Die Zeit des Weltbildes», situa o início dos Tempos Modernos na metafísica de Descartes, na qual a verdade é concebida como «certeza da representação» e que permite assim ao homem tornar-se sujeito, esta palavra designando «o que jaz adiante (das Vor-Liegende) e que, enquanto fundo, reúne tudo sobre si.» ${ }^{9}$ Mas é também o que faz Foucault, o qual, ao contrário de Heidegger, insiste sobre uma ruptura entre duas épocas profundamente distintas, a Idade Clássica das primeiras décadas do século XVII até ao final do século XVIII, e a modernidade, a partir do início do século XIX, esta última sendo a única que torna possível um pensamento do homem. Tal como Nietzsche com o sobre-homem, também Heidegger com o Dasein e Foucault com o si e o nós propõem sujeitos que substituem o homem, embora o próprio termo de sujeito talvez não convenha inteiramente para designar as figuras que intervêm nesta substituição. A ontologia fundamental apresentou-se como um outro discurso sobre o homem, que ela pretendeu analisar de maneira inédita com o auxílio de um Dasein marcado por uma estrutura própria. Como escrevia Heidegger em Ser e Tempo, «este ente que somos sempre nós mesmos e que tem entre outras a possibilidade de ser do perguntar, fixamo-lo terminologicamente como Dasein» ${ }^{10}$. A onto-

\footnotetext{
${ }^{8}$ Foucault, Les Mots et les choses, Paris, Gallimard, 1966.

${ }^{9}$ Heidegger, Holzwege, Gesamtausgabe 5, p. 81.

${ }^{10}$ Heidegger, Sein und Zeit, Gesamtausgabe 2, p. 7.
} 
logia crítica de nós mesmos que lhe sucedeu pôs no centro das suas preocupações novos entes (o si e o nós) que reconfiguram o campo do problema. Mensch, Übermensch, Dasein, soi e nous são reanimações do problema; não naturezas, mas nomes de um campo; não essências, mas configurações instauradas a partir de pontos de vista diferentes. Podemos então afirmar que a morte do homem, em vez de acabar de uma vez por todas com o problema, fá-lo reaparecer com contornos inesperados. Todos estes autores nos mostram que a questão do homem volta e não pára de voltar, e que sempre volta transformada, por vezes totalmente, o que nos impede de crer que sob o mesmo nome de homem se encontraria um objecto constante, preso numa configuração imutável.

\section{Essência, identidade e subjectividade na era pós-antropológica}

Regressemos agora à Antropologia para notar como Kant prepara o terreno que lhe permitirá responder à pergunta sobre o ser do homem. A forma desta resposta é implícita nos termos do projecto pragmático: definir o homem é saber a um tempo o que ele faz, o que pode fazer e o que deve fazer de si mesmo. O programa antropológico não se satisfaz portanto nem com uma simples história do passado, nem com uma genealogia da actualidade. Ele não se contenta com um trabalho descritivo, mas exige uma reflexão prospectiva e mesmo normativa, Kant tendo compreendido que quando sabemos como o homem se tornou o que é, o problema (do homem) mais não faz que começar. Neste aspecto ele permanece fiel ao espírito das interrogações formuladas noutros lugares, desde logo na Crítica da razão pura, onde expunha as três perguntas que encerravam «todo o interesse» da razão, «tanto especulativo como prático»: «1. Que posso saber? 2. Que devo fazer? 3. Que me é permitido esperar?»1. Was ken itch wisent? 2. Was soll ich tun? 3. Was darf ich hoffen? (Kant, $K r V$ : B 832-B 833); e posteriormente na Lógica, onde as mesmas questões eram retomadas, e referidas a uma quarta, "Was ist der Mensch?» (Kant, Logik: 25). Na tese complementar que consagrou à $\mathrm{An}$ tropologia, Foucault interpreta o «conteúdo [...] da quarta pergunta» como não sendo «fundamentalmente diferente do sentido que tinham as três primeiras; e o facto de estas remeterem para a última não significa nem que desapareçam nela, nem que dependam de uma nova interrogação que as ultrapassa, mas simplesmente que a questão antropológica $f a z$, retomando-as, as perguntas que se reportam a ela.» ${ }^{11}$ Pelo menos em parte esta afirmação surpreende, pois o sujeito da quarta pergunta está, na ver-

${ }^{11}$ Foucault, «Introduction à l'Anthropologie de Kant» (1960), in op. cit., p. 52. Conservamos os sublinhados de Foucault no seu dactiloscrito de 1960, suprimidos na edição Vrin. 
dade, ausente das três primeiras: nestas trata-se de um $e u$, ao passo que na última se trata do homem. Há portanto nesta transição um salto da singularidade para a universalidade que não é anódino e não pode ser ignorado. A passagem do eu ao homem apenas é possível uma vez suposto o parentesco formal entre a universalidade e a singularidade, como faz Kant desde a interpretação que dá da tábua dos juízos na Crítica da razão pura (Kant, KrV: B 96). Somente nesta perspectiva o eu e o homem se tornam comutáveis, procedimento que deveria reter mais a nossa atenção. $\mathrm{O}$ aparecimento do homem onde antes só havia $e u$, o pressuposto da equivalência entre a singularidade e a universalidade, e ainda o relevo dado ao ser deste homem, eis três modificações de vulto que marcam o surgimento da quarta pergunta. Só quando reconhecermos esta tripla operação, e não enquanto a ignorarmos, seremos capazes de compreender plenamente a metamorfose da configuração antropológica introduzida pela obra de Kant.

Além disso, nesse momento unicamente poderá ser equacionada uma saída da situação, como fez Nietzsche com o Übermensch, elevando-se a um patamar superior ao do Mensch; ou ainda Lévi-Strauss, ao declarar na Pensée sauvage «que o objectivo último das ciências humanas não é o de constituir o homem, mas o de dissolvê-lo.» ${ }^{12}$ Überwindung e dissolução são duas vias possíveis, uma por cima, outra por baixo, para abandonar o quadro antropológico delimitado por Kant. Uma outra via ainda consistiria em seguir o movimento interrogativo kantiano sem contudo transpor a barreira da universalidade. Neste caso, a quarta pergunta não seria mais «o que é o homem?», mas «o que sou eu?», visto que eu é o único sujeito presente desde o início. Ora, se é verdade que esta formulação opera ainda a passagem do ente ao ser, posto continuar a tratar-se, nos termos, de uma pesquisa sobre o que é um ente determinado, também deve reconhecer-se que ela se afasta da captação de uma essência e se aproxima de uma procura da identidade singular. O modo kantiano de fazer a quarta pergunta velava e até entravava esta possibilidade, visto apoiar-se sobre o plano do universal e reduzir o espaço para uma real tomada em conta tanto das singularidades quanto das particularidades: estas estavam puramente ausentes do questionamento, enquanto aquelas se subsumiam no universal ${ }^{13}$. A partir de agora, desligando-se o comutador universal, mecanismo argumentativo pelo qual o singular é sempre e desde o início directamente subordinado ao princípio de universalidade, abre-se um acesso ao singular enquanto tal, mas também ao particular e, de um modo que ainda será preciso aprofundar, a uma relação possível entre ambas as instâncias. A possibilidade

12 Claude Lévi-Strauss, La Pensée sauvage, Paris, Plon, 1962, p. 326.

${ }^{13}$ Daí o lugar curioso que a Antropologia de um ponto de vista pragmático guarda para as particularidades humanas, por exemplo na exposição das diferenças entre os povos ( «O carácter do povo»). 
criada pelo abandono da questão antropológica kantiana é então dupla: sem homem nem universal, apoiada sobre o singular e o particular, a nova configuração do problema passa a ser determinada por um «que sou eu?» que se desdobra num «que somos nós?».

Em vez de reencontrarmos por esta via o problema da essência, é um outro, duplo, da identidade e da subjectividade que descobrimos. Neste novo plano deixa de haver pretexto para que a identidade e a subjectividade sejam vistas à luz da essência, no que constituiria uma submissão renovada dos poderes que acabaram de ser libertados do jugo do universal. Ao mesmo tempo nada disto significa que tenhamos de renunciar definitivamente ao universal. Se Apollinaire era justo ao apresentar como única condição do grande achado a mais intensa das perdas - «Perder/ Mas perder a sério/ Para dar largas ao achado», escrevia ele) ${ }^{14}$, então o nosso escape temporário aos encantos do universal poderá também ser um primeiro passo, necessário, para que possa voltar-se a este no futuro, porém de maneira renovada. Até lá compreenda-se bem o programa propriamente filosófico que se impõe: ele não é dominado por uma nova busca do conceito de homem nem tão-pouco por uma demanda do conceito de eu, como poderíamos ser levados a crer erradamente diante da presença do pronome pessoal. Se urge reatar com o problema «homem» reconfigurando-o, isto só será possível evitando o erro de pretender dar do homem um novo conceito que dele enuncie a verdade. O homem é apenas o nome de um espaço problemático. Nada neste nome deve convidar a que se regresse a um conceito substancial. Tudo deve conduzir a que se acolha plenamente um nominalismo antropológico.

Ao reler o livro de Kant, Dietmar Kamper escrevia, numa fórmula em guisa de paradoxo, que «ainda esperamos um conceito de homem que permita demonstrar conceptualmente a impossibilidade de um conceito de homem.» ${ }^{15}$ Tal conceito, que como se vê é intrinsecamente contraditório, permanece impossível de ser dado e é por isso que não temos de esperá-lo, a locução libertando desde logo toda a sua pujança irónica. Para levá-la às últimas consequências é indispensável pensar o homem sem dar-lhe (e sem dar dele) um novo conceito, e pensar a humanidade sem um conceito de humanidade. De tal modo que a pergunta que se impõe não é mais «o que é o homem?», mas «que poderá significar "pensar o homem e a humanidade sem um conceito de homem nem de humanidade"?» Por outras palavras, que poderá ser uma humanidade sem conceito, sem essência, sem «o que é»?

14 Guillaume Apollinaire, «Toujours», Calligrammes.

15 «Ein Begriff vom Menschen, der es erlaubt, die Unmöglichkeit eines Begriffs vom Menschen begrifflich nachzuweisen, steht noch aus.» D. Kamper, «Die Geschoßbahn der Frage: Was ist der Mensch?», Paragrana, Band 11, Heft 2, 2002: Kants Anthropologie, dir. D. Kamper, C. Wulf e G. Gebauer, p. 39. 
Suponhamos um instante que a essência se liga à identidade e à subjectividade como a natureza ao que é construído. Neste caso deveremos admitir que a Antropologia encerra já o princípio da sua própria ultrapassagem, na medida em que se interroga pragmaticamente menos sobre o que a natureza fez do homem do que sobre o que este fez, pode fazer e deve fazer de si mesmo. Pelo menos em parte, o homem é para Kant uma construção ainda não perfeita. Se prolongarmos este modo de pensar até ao domínio do eu e do nós, notar-se-á que nós somos também (embora não só) o que fizemos de nós mesmos, e talvez sejamos ainda o que podemos e devemos fazer de nós mesmos. No plano pessoal, eu sou igualmente (embora não só) o que fiz de mim mesmo, e com certeza ainda o que posso e o que devo fazer de mim mesmo. A configuração do problema «homem» aparece aqui sob uma nova luz e encontra-se, por esta via, fortemente transformada, porquanto compreendemos doravante que são os seus limites que se encontram em jogo, tanto quanto as fronteiras que a atravessam e desenham nela territórios. Kant sabia-o já quando pensava no bem e no mal e se esforçava por separá-los, traçando entre eles a linha do permitido. Ora, se nos aparece come demasiado longínquo o modo singular segundo o qual a Antropologia define o campo do humano, é precisamente porque ela sabe ainda o que são o bem e o mal. Estas noções parecem hoje perdidas, ou então foi a evidência da fronteira que as separava que se esbateu, de tal sorte que nos confrontamos com conceitos demasiado gerais como a violência ou o poder, a respeito dos quais nos vemos obrigados a lembrar regularmente que eles não são nem bons nem maus, que eles são o que são e que tudo depende do que se faz deles e de «quem fala» ${ }^{16}$. Dever-se-ia neste momento reinventar o bem e o mal, traçando uma nova fronteira que os separe? Em que medida esta renovação da partilha do espaço humano implica um deslocamento dos limites exteriores do problema no seu conjunto? Certo é que este problema sendo

16 Daí o interesse para nós da contribuição de Benjamin a uma «crítica da violência», labor que passa necessariamente por um estudo das relações entre os meios e os fins do uso desta violência, implícitos nomeadamente nas noções de direito natural e direito positivo. Se na crítica esboçada por Benjamin é preciso ouvir o eco kantiano de um estudo das condições de possibilidade de um uso legítimo-racional da Gewalt, é também porque se deve ir além do exame que trata somente do ponto de partida da força (ou que quer responder à pergunta «quem fala?»). Resta no entanto saber quem julga a bondade ou a malvadez dos meios e dos fins e, consequentemente, da legitimidade do uso da força. Sobre este assunto ver Benjamin, «Zur Kritik der Gewalt» (1921), Gesammelte Schriften, vol. II-1, Frankfurt am Main, Suhrkamp Verlag, 1974-1989, bem como o verbete de Étienne Balibar, «Gewalt», in Wolfgang Fritz Haug (dir), Historisch-Kritisches Wörterbuch des Marxismus, vol. 5: Gegenöffentlichkeit bis Hegemonialapparat, Hamburg, Argument Verlag, 2001 (versão francesa acessível em http://ciepfc.rhapsodyk.net/article.php3?id _article $=49$, consultada em 10/02/2008). 
um espaço, as linhas que o percorrem e fixam dependem de uma construção (o que eu faço, o que nós fazemos) e são por conseguinte eles próprias construções que trazem consigo as marcas das lutas tanto teóricas quanto práticas que travo comigo mesmo ou que travamos connosco ou contra nós mesmos e contra outros, lutas de que estas linhas são o resultado provisório. O problema do humano é também, numa proporção que não devemos nem sobrestimar, nem subestimar, um Kampfplatz, o que não significa de modo algum que este Kampf seja desprovido de regras nem que ele se confunda com uma guerra.

Voltemos, para concluir, ao início da nossa exposição. O que impressiona na leitura da primeira citação que fizemos não é somente a sua força conceptual, é também o sentimento que nos dá de uma profunda actualidade. Acreditamos, apesar de todas as vicissitudes, viver numa constituição republicana, e empenhamo-nos cada dia para que o maior número tenha acesso aos meios que lhe permitam desenvolver as suas (por assim dizer) disposições para o bem. Porém, à nossa volta a violência grassa. É por isso tempo de perguntar de novo o que somos, isto é, o que fizemos, o que podemos fazer e o que devemos fazer de nós mesmos. Dito de outro modo, precisamos reinventar a configuração do problema que somos. Como ponto de partida para esta reinvenção, o mundo de hoje impõe-nos a violência sob as suas diferentes formas, entre as quais a guerra é apenas um exemplo. Como pensar a uma nova luz a violência de que o ser humano é capaz? Talvez repartindo da ideia segundo a qual a animalidade é, nas suas expressões, anterior e no fundo mais potente que a pura humanidade, como sugeriu Kant, mas desta feita para conduzi-la ao paroxismo. Não quererá ela dizer, com efeito, que ao contrário do que se poderia crer não existe um resto de animalidade no homem, mas que é a humanidade que existe no animal, do qual ela é uma dobra e um acidente? Que portanto a humanidade não é infinitamente mais digna que todos os outros seres vivos sobre a terra, ao contrário do que afirmava Kant logo no início da Antropologia (Kant, Anth., p. 127), mas simplesmente um ser no qual a animalidade se manifesta de maneira específica ou segundo a espécie? Como retraçar a partir daqui as fronteiras do bem e do mal e da legitimidade do uso da força? São perguntas urgentes para a filosofia, mas com certeza também para a ciência e a arte, se é verdade que para sair da violência actual nos falta ainda compreender como nos transformámos naquilo que somos e fazer um esforço para sermos de outro modo. 


\section{RESUMO}

À pergunta «o que é o homem?» deve começar por responder-se que ele é apenas o nome de um espaço. A configuração deste espaço, isto é os limites que o definem e as linhas que desenham territórios no seu interior, muda com o tempo. De tal modo que a história do homem, filosoficamente compreendido, pode ser contada a partir do estudo de diferentes configurações problemáticas. Impossível é responder definitivamente à pergunta pela essência do homem. $\mathrm{O}$ nominalismo espácio-antropológico é aqui desenvolvido com o auxílio da perspectiva kantiana, segundo a qual o homem está dividido entre uma disposição para o bem e uma inclinação pelo mal. Esta coincide com a animalidade, ao passo que aquela se confunde com a humanidade. Tal concepção permite explorar três temas importantes: primeiro, o de uma antropologia da violência, que consiste no estudo da força que deve ser exercida por certos homens (os educadores) para amansar os outros. O segundo problema é o da natureza da pergunta «que é o homem?», tratada aqui sob um triplo aspecto: do ponto de vista pragmático, definir o homem é saber a um tempo o que ele faz, o que pode fazer e o que deve fazer de si mesmo. Enfim, terceiro problema, o da passagem do eu nas perguntas «que posso saber?», «que devo fazer?» e «que me é permitido esperar?» ao homem, na quarta pergunta. No tratamento destes temas, a solução nominalista substitui a procura de uma essência por um trabalho sobre a identidade e a subjectividade.

\section{RÉSUMÉ}

À la question «qu'est-ce que l'homme?» il faut répondre qu'il n'est que le nom d'un espace. La configuration de cet espace, ou les limites qui le définissent et les lignes qui à l'intérieur de lui dessinent des territoires, change dans le temps. Si bien que l'histoire de l'homme philosophiquement compris peut être racontée à partir de l'étude de différentes configurations problématiques. Il est en tout cas impossible d'apporter une réponse définitive à la question de l'essence de l'homme. Pour développer le nominalisme spatio-anthropologique nous prendrons appui sur la perspective kantienne, selon laquelle l'homme est divisé par une disposition pour le bien et une inclination au mal. Celle-ci se confond avec l'animalité, tandis que celle-là recoupe l'humanité. Cette conception fraye la voie au traitement de trois problèmes majeurs: d'abord, celui d'une anthropologie de la violence, touchant à l'étude de la force qui doit être exercée par certains hommes (les éducateurs) afin d'en apprivoiser d'autres. Ensuite il y a le problème de la question «qu'est-ce que l'homme?», que nous traitons sous trois aspects: définir l'homme d'un point de vue pragmatique, c'est savoir à la fois ce qu'il fait, ce qu'il peut faire et ce qu'il doit faire de lui-même. Enfin il y a le problème du passage du je dans les questions «que puis-je savoir?», «que dois-je faire?» et «que m'est-il permis d'espérer?» à l'homme, dans la quatrième question. Dans le cours de l'analyse, la solution nominaliste remplace la recherche d'une essence par un travail sur l'identité et la subjectivité. 